\title{
Caudal Epidural Injections with Sarapin or Steroids in Chronic Low Back Pain
}

\author{
Laxmaiah Manchikanti, MD*, Vidyasagar Pampati, MSc ${ }^{\star *}$, Jose J. Rivera, MD ${ }^{\Omega}$, Carla Beyer, RN"\#, \\ Kim S. Damron, RN"\#, and Renee C. Barnhill, RN"\#
}

Epidural steroid injections are the most commonly used procedures to manage chronic low back pain in interventional pain management settings. Approaches available to access the epidural space in the lumbosacral spine include the interlaminar, transforaminal, and caudal. The overall effectiveness of epidural steroid injections has been highly variable.

This study included 65 patients who underwent diagnostic facet joint nerve blocks utilizing comparative local anesthetic blocks and were shown to be negative for facet joint pain and other problems such as sacroiliac joint pain before enrollment into the study. They were randomly selected from 105 patients negative for facet joint pain allocated into three groups, with Group I consisting of 15 patients comprising a convenience control sample treated conservatively; Group II, consisting of 22 patients treated with caudal epidural with local anesthetic and Sarapin ${ }^{\circledR}$; and Group III, consisting of 33 patients treated with caudal epidural with a mixture of local anesthetic, and betamethasone. The study period lasted for 3 years.

Results showed that there was significant improvement in patients receiving caudal epidural injections, with a decrease in pain associated with improved physical, functional and mental status; and decreased narcotic intake combined with return to work. The study showed that at 1 month $96 \%$ of the patients evaluated showed significant improvement, which declined to $56 \%$ at 3 months and $16 \%$ at 6 months, with administration of 1 to 3 injections. Cumulative relief with 1 to 12 injections was noted in $96 \%$ of the patients at 1 month, $95 \%$ at 3 months, $85 \%$ at 6 months, and $67 \%$ at 1 year. The study also showed cost effectiveness of this treatment, with a cost of $\$ 2550$ for 1-year improvement of quality of life .

In conclusion, caudal epidural injections with steroids or Sarapin are an effective modality of treatment in managing chronic, persistent low back pain that fails to respond to conservative modalities of treatments and is also negative for facet joint pain. The treatment is not only effective clinically but also is cost effective.

Keywords: Chronic low back pain, caudal epidural injections, epidural steroids, betamethasone, Sarapin

or severe disability (22). Back pain is prevalent in $12 \%$ of children and adolescents, $15 \%$ of adults, and $27 \%$ of the elderly (20). The prevalence of chronic, persistent low back pain at 12 months is shown to be $28 \%$ to $75 \%$, in contrast to the earlier reports of $10 \%(1,20)$.

Approaches available to access the epidural space in the lumbosacral spine include the interlaminar, transforaminal, and caudal. The first reports of management of low back and lower-extremity pain were of Sicard (23), and Pasquier and Leri (24) in 1901. Interlaminar epidural injections utilizing a paramedian approach were proposed by Pages in 1921 (25).

From Pain Management Center of Paducah, Paducah, Kentucky. *Medical Director, **statistician, ${ }^{*}$ interventional pain physician, and ${ }^{\# \#}$ clinical coordinators at the Pain Management Center of Paducah. Address correspondence: Laxmaiah Manchikanti, MD, 2831 Lone Oak Road, Paducah, Kentucky 42003. E-mail: drm@asipp.org
Since the introduction of epidural injections in the early 1900s, numerous publications have appeared in support and some in opposition of epidural injections in managing low back pain or lower extremity pain. Along with 
these reports numerous systematic reviews of the effectiveness of epidural steroid injections have also appeared, with conflicting opinions $(1,9-12,14-17,19)$. The overall effectiveness of epidural steroid injections has been highly variable. Perceived advantages and disadvantages of each of the three approaches, (ie, interlaminar, caudal, and transforaminal injections) also have been described (1). Even though interlaminar lumbar epidural steroid injections have been studied more extensively than either caudal or transforaminal routes, more opinions have been expressed in favor of caudal epidural steroid injections, as well as transforaminal epidural injections $(1,9,11,26)$. Target specificity has been an important aspect of epidural steroid injections (26). In addition, in almost all studies, epidural steroid injections were administered without fluoroscopy except in transforaminal and a few caudal epidural steroid injection studies; and the patients selected were heterogeneous.

Tissues in the low back capable of transmitting pain include muscles, ligaments, fascia, discs, nerve root dura, and facet joints (27). It is difficult to identify the causative factor for low back pain which may be either a facet joint or disc or another structure, which, generally, is differentiated based on clinical features of somatic/referred pain or radicular pain (1). Chronic low back pain is a diagnostic dilemma in $85 \%$ of patients, even in experienced hands with all of the available technology (1). Considering the above factors, it is logical to assume that, in some cases, epidural steroids were not indicated or delivery of steroids was not target specific. In addition, it is believed that the benefits of epidural steroid injections may be twofold. The explanations are based in part on the pharmacological and physical actions of local anesthetics, corticosteroids, and other agents, as well as physical effects, including clearing of the adhesions or inflammation from the vicinity of the nerve root sleeve (1). Thus, it is not quite certain at this point whether steroid administration is essential to achieve a therapeutic effect, even though the results have shown better therapeutic results when steroid was administered rather than the local anesthetic alone. In addition to local anesthetic and steroids, Sarapin ${ }^{\circledR}$ (High Chemical, Levittown, PA) is another agent used in neural blockade. Sarapin has been shown to provide significantly longer relief than local anesthetic and relief almost equal to methylprednisolone acetate (DepoMedrol@) in both diagnostic as well as therapeutic facet joint nerve blocks $(28,29)$. However, there are no studies or reports in the literature evaluating the effectiveness of Sarapin in caudal epidural injections.
Hence, this study was designed and undertaken to evaluate the role of a mixture of a local anesthetic and Sarapin or local anesthetic and steroids in managing chronic low back pain. The issues explored included duration of relief with caudal epidural injections with local anesthetic and Sarapin or local anesthetic and steroids, in a prospective study evaluating significant pain relief, overall health status, drug intake, and cost-effectiveness.

\section{METHODS}

This study included 65 patients divided into three groups derived from a sample of 200 consecutive patients seen in one private pain management practice in a nonuniversity setting. Patients younger than 18 years or older than 90 years, those who exhibited neurological deficits, those who had had pain for less than 6 months, those who had responded to conservative management, and those who had undergone neural blockade in the past were excluded.

All patients consented to participate. Initially, all the patients (200) underwent diagnostic facet joint nerve blocks on one or two separate occasions using lidocaine $1 \%$ and bupivacaine $0.25 \%$ (30). Following the diagnostic blocks, $42 \%$ of the patients, or 84 , were diagnosed with facet joint pain based on controlled, comparative local anesthetic blocks. Eleven patients had other problems such as sacroiliac joint pain. Of the remaining 105 patients, 65 were randomly allocated to this study group; further allocation into three groups was by patient choice. Group I consisted of 15 patients comprising a convenience sample that was considered as a control group treated conservatively, due either to nonapproval of the treatment or the patient's desire to undergo conservative treatment. Group II consisted of 22 patients treated with caudal epidural with local anesthetic and Sarapin, whereas Group III consisted of 33 patients treated with caudal epidural with a mixture of local anesthetic and betamethasone. The study period lasted from January 1998 to December 2000, providing 3 years of management and follow-up.

The evaluation included data collection as to the variables of age, gender, duration of pain in months, nature of onset, height, weight, and history of previous surgical interventions; the number of injections received by each patient in each group; the quality and duration of pain relief; overall health status in pre- and post-treatment phases; psychological status in pre- and post-treatment phases; narcotic intake in pre- and post-treatment periods; and employment and work status in pre- and post-treatment periods. The quality of pain relief was characterized as less 
than $50 \%$ relief, or greater than $50 \%$ relief. Pain relief greater than $50 \%$ was considered significant, and these patients were characterized as successful, with "significant pain relief."

All procedures were performed by one physician in an ambulatory surgery setting, either in a sterile operating room or a treatment room. All caudal epidural injections were performed under fluoroscopy, with patients in the prone position, under appropriate monitoring with intravenous (IV) access and sedation with midazolam and fentanyl. With sterile preparation, access to the epidural space was obtained and then confirmed by injection of nonionic contrast. Following this, based on each patient's contrast flow and distribution, $10 \mathrm{~mL}$ to $20 \mathrm{~mL}$ mixture was injected. Group II received a mixture of local anesthetic with lidocaine hydrochloride (Xylocaine ${ }^{\circledR}$ ) and Sarapin, whereas Group III received local anesthetic and $6 \mathrm{mg}$ of betamethasone.

Following the blocks, the patients were discharged home. Upon a return visit, each patient was evaluated for amount of relief of pain on the basis of a numeric and verbal painrating scale, perceived physical health by the patient and physician, perceived mental health by the physician and patient, and perceived functional status by the patient and physician. Patients were also evaluated at each visit as to narcotic intake. All features were evaluated at each visit by a treating physician and at the end of treatment by a physician not involved in treatment, and the data were tabulated. Any potential complications were also evaluated at each visit.

Demographic features of age, mode of onset of pain, work status, history of surgery, and other historical features were obtained from the patient history and recorded. The patient's age was calculated from his/her birth date, whereas duration of pain was calculated based on the patient's memory of the onset of pain to the closest month, when available. Pain characteristics were obtained from the history, comprehensive pain questionnaire, and pain diagram. Pain rating was obtained from a 10-point numeric and verbal pain-rating scale. Average pain, physical health, mental health, and functional status were determined from multiple sources, including patient description of the pain; and patient perception of physical health, mental health and functional status; as well as objective evaluations performed with psychological evaluation and range-of-motion evaluation and ability to function and carry on important activities the patient was unable to perform prior to the intervention. Psychological status was determined by a psychological questionnaire, as well as psychological evaluation utilizing Millon Clinical Multiaxial Inventory (MCMI-II) and Beck's Depression Inventory. Major depression, generalized anxiety disorder, and somatization disorder were determined from these tests. Symptom magnification was determined utilizing a set of signs and symptoms that included multiple items: strategy to control symptoms, control over environment, overt pain behavior, pain rating, pain diagram, nonphysiologic symptoms and signs, presence or absence of objective signs, laboratory evidence, coefficient of variation with functional testing, cooperation with evaluation and presence or absence of somatization as determined by MCMIII. Narcotic intake was determined as none, mild, moderate, and heavy based on the dosage, frequency and class of drug. Intake of class IV narcotics, ie, propoxyphene napsylate (Darvocet $\left.{ }^{\circledR}\right)$, pentazocine hydrochloride (Talwin $\AA$ ), on tramadol hydrochloride (Ultram $®$ ), up to a maximum of four times, or hydrocodone twice or less per day, was considered as mild; intake of class III narcotics, ie hydrocodone, up to four times, as moderate; and intake of class II narcotics, (ie, oxycodone, morphine, meperidine, transdermal fentanyl, and methadone) in any dosage was considered as heavy. Employment and work status classified as employed, unemployed, housewife, disabled, and retired were also determined from the pretreatment and post-treatment work status. Only employed and unemployed patients were considered to be eligible for employment, whereas disabled patients and patients over 65 were considered not employable; however, data were tabulated if any of these patients returned to work. The data were evaluated and confirmed by one of the two physicians who were not performing the blocks and treating the patients.

Data were recorded on a database using Microsoft ${ }^{\circledR}$ Access $®$; the SPSS Version 9.0 statistical package was used to generate frequency tables, and the chi-squared statistic was used to test the significant difference between groups. Fisher's Exact Test was used wherever expected value was less than five. Student's t-test was used to test mean difference between groups. Results were considered statistically significant if the $P$-value was less than 0.05 .

\section{RESULTS}

\section{Patient Characteristics}

Demographic data are shown in Table 1, with no significant differences noted between groups in terms of age, weight, height, mode of onset of pain, duration of pain, and history of previous surgical intervention. However, 
Table 1. Patient Characteristics

\begin{tabular}{|c|c|c|c|c|}
\hline Number of patients & & $\begin{array}{c}\text { Group I } \\
\mathrm{N}=16\end{array}$ & $\begin{array}{c}\text { Group II } \\
\mathbf{N}=\mathbf{2 2}\end{array}$ & $\begin{array}{c}\text { Group III } \\
\qquad \mathbf{N}=\mathbf{3 3}\end{array}$ \\
\hline \multirow{2}{*}{ Gender } & Men & $69 \%(11)$ & $45 \%(10)$ & $27 \%(9)$ \\
\hline & Women & $31 \%(5)$ & $55 \%(12)$ & $73 \% *(24)$ \\
\hline \multirow{2}{*}{ Age (yrs.) } & Range & $32-77$ & $31-83$ & $27-87$ \\
\hline & Mean + SEM & $48.8+3.63$ & $49.1+3.38$ & $48.3+2.85$ \\
\hline \multirow{2}{*}{ Weight (lbs.) } & Range & $127-280$ & $121-276$ & $106-300$ \\
\hline & Mean + SEM & $181+11.1$ & $188+9.7$ & $169+8.0$ \\
\hline \multirow{2}{*}{ Height (inches) } & Range & $61-74$ & $51-72$ & $59-73$ \\
\hline & Mean + SEM & $68.4+0.84$ & $66.2+0.97$ & $65.6+0.64$ \\
\hline Body Mass Index & & $27.1+1.44$ & $30.3+1.59$ & $27.7+1.3$ \\
\hline \multirow{2}{*}{ Mode of onset of pain } & Following an incident & $43 \%(7)$ & $54 \%(12)$ & $48 \%(16)$ \\
\hline & Gradual onset & $57 \%(9)$ & $46 \%(10)$ & $52 \%(17)$ \\
\hline \multirow{2}{*}{ Duration of pain (years) } & Range & $0.5-25$ & $0.5-25$ & $0.5-20$ \\
\hline & Mean + SEM & $8.8+1.81$ & $7.8+1.67$ & $5.9+0.85$ \\
\hline Postsurgical & & $19 \%(3)$ & $36 \%(8)$ & $30 \%(11)$ \\
\hline
\end{tabular}

Table 2. Details of multiple procedures

\begin{tabular}{|c|c|c|c|c|c|c|}
\hline \multirow[b]{2}{*}{ Multiple procedures } & \multicolumn{2}{|c|}{ Group II } & \multicolumn{2}{|c|}{ Group III } & \multicolumn{2}{|c|}{ Total (Groups II and III) } \\
\hline & Number & $\%$ & Number & $\%$ & Number & $\%$ \\
\hline One & 22 & $100 \%$ & 33 & $100 \%$ & 55 & $100 \%$ \\
\hline Two & 22 & $100 \%$ & 33 & $100 \%$ & 55 & $100 \%$ \\
\hline Three & 20 & $91 \%$ & 30 & $91 \%$ & 50 & $91 \%$ \\
\hline Four & 19 & $86 \%$ & 28 & $85 \%$ & 47 & $85 \%$ \\
\hline Five & 17 & $77 \%$ & 25 & $76 \%$ & 42 & $76 \%$ \\
\hline Six & 17 & $77 \%$ & 21 & $64 \%$ & 38 & $69 \%$ \\
\hline Seven & 15 & $68 \%$ & 18 & $55 \%$ & 33 & $60 \%$ \\
\hline Eight & 12 & $55 \%$ & 16 & $48 \%$ & 28 & $51 \%$ \\
\hline Nine & 9 & $41 \%$ & 12 & $36 \%$ & 21 & $38 \%$ \\
\hline Ten & 7 & $32 \%$ & 9 & $27 \%$ & 16 & $29 \%$ \\
\hline Eleven & 6 & $27 \%$ & 1 & $3 \%$ & 7 & $13 \%$ \\
\hline Twelve & 4 & $18 \%$ & 1 & $3 \%$ & 5 & $9 \%$ \\
\hline
\end{tabular}


Table 3. Comparison of number of interventions at various levels of study period

\begin{tabular}{lccc}
\hline & Group II & Group III & Total (Groups II and III) \\
\cline { 2 - 4 } 3 months & $3.1+0.18(21)$ & $3.1+0.14(31)$ & $3.1+0.11(52)$ \\
6 months & $4.5+0.26(19)$ & $4.5+0.18(29)$ & $4.5+0.15(48)$ \\
1 year & $6.4+0.36(18)$ & $6.3+0.30(23)$ & $6.4+0.23(41)$ \\
2 years & $8.7+0.78(15)$ & $9.5+0.42(13)$ & $9.1+0.46(28)$ \\
\hline
\end{tabular}

the ratio of women in Group III was higher than in Group I and Group II.

\section{Injection Characteristics}

Table 2 illustrates the details of patients undergoing multiple procedures over a period of 3 years. Sixty percent of the patients underwent seven procedures, which was reduced to $51 \%$ for eight procedures, $29 \%$ for ten procedures, and $9 \%$ for 12 procedures.

As shown in Table 3, the mean number of interventions was from $3.1+0.11$ at 3 months, whereas it was $4.5+$ 0.15 at 6 months, $6.4+0.23$ at 12 months, and $9.1+0.46$ at 2 years. There were no significant differences noted between the groups with multiple procedures, or mean episodes of medial branch blocks.

Table 4 shows the proportion of patients who continued in the study, at various intervals during a 3-year period. Patients who failed to respond at various levels were provided with other treatments, with or without interventional procedures.

\section{Pain Relief}

Table 5 shows significant relief with each injection. There was no significant difference noted among groups with any injection throughout the course of treatment with 1 to 12 injections. Relief ranged from 0 to 104 weeks, with mean relief ranging from $3.1+0.33$ weeks to $14.6+1.71$ weeks. Average relief for all patients and all injections was $9.7+$ 0.48 weeks.

Fig. 1 illustrates cumulative relief $(>50 \%)$ with one to three injections; $96 \%$ of the patients experienced relief lasting 1 month, which declined to $56 \%$ at 3 months, and to $16 \%$ at 6 months. Fig. 2 illustrates cumulative relief with 1 to 12 injections, which also declined with time.

\section{Overall Health Status}

Table 6 shows significant overall improvement in health status, with improvement in both treatment groups; whereas the control group failed to show any difference.

\section{Psychological Status}

Psychological status evaluation (Table 7) showed no significant differences between treatment periods, pre- and post-treatment in Group I. However, significant improvement was seen in treatment groups, specifically with somatization, and symptom magnification aspects.

Table 4. Illustration of proportion of patients in the study at various times during the study period

\begin{tabular}{lccc}
\hline Study period & Group I (16) & Group II (22) & Group III (33) \\
\cline { 2 - 4 } Initial & $100 \%(16)$ & $100 \%(22)$ & $100 \%(33)$ \\
3 months & $100 \%(16)$ & $96 \%(21)$ & $94 \%(31)$ \\
6 months & $88 \%(14)$ & $86 \%(19)$ & $88 \%(29)$ \\
1 year & $81 \%(13)$ & $82 \%(18)$ & $70 \%(23)$ \\
2 years & $37 \%(6)$ & $68 \%(15)$ & $42 \%(14)$ \\
\hline
\end{tabular}


Table 5. Comparison significant relief (>50\%) with each injection by group in weeks

\begin{tabular}{lcccccc}
\hline \multirow{2}{*}{ Injection } & \multicolumn{2}{c}{ Group II } & \multicolumn{2}{c}{ Group III } & \multicolumn{3}{c}{ Total (Groups II and III) } \\
\cline { 2 - 7 } Number & Mean + SEM & Range & Mean + SEM & Range & Mean + SEM & Range \\
One & $3.1+0.51(22)$ & $0-9$ & $3.1+0.44(33)$ & $0-9$ & $3.1+0.33(55)$ & $0-9$ \\
Two & $9.7+4.52(22)$ & $0-104$ & $5.8+0.82(33)$ & $0-26$ & $7.4+1.87(55)$ & $0-104$ \\
Three & $7.9+0.85(20)$ & $4-21$ & $7.7+0.78(30)$ & $3-26$ & $7.7+0.57(50)$ & $3-26$ \\
Four & $12.2+3.57(19)$ & $4-76$ & $9.0+0.82(28)$ & $2-26$ & $10.3+1.52(47)$ & $2-76$ \\
Five & $10.4+0.71(17)$ & $4-17$ & $16.4 *+4.07(25)$ & $0-102$ & $14.0+2.46(42)$ & $0-102$ \\
Six & $9.9+1.00(17)$ & $1-17$ & $10.9+0.95(21)$ & $4-26$ & $10.5+0.69(38)$ & $1-2$ \\
Seven & $12.5+0.77(15)$ & $9-17$ & $13.3+2.45(18)$ & $0-52$ & $12.9+1.36(33)$ & $0-52$ \\
Eight & $13.7+0.96(12)$ & $9-21$ & $11.3+0.89(16)$ & $3-17$ & $12.3+0.68(28)$ & $3-21$ \\
Nine & $11.8+1.22(9)$ & $2-13$ & $13.0+0.70(12)$ & $9-17$ & $12.5+0.65(21)$ & $2-17$ \\
Ten & $16.1+3.85(7)$ & $9-39$ & $13.4+0.80(9)$ & $9-17$ & $14.6+1.71(16)$ & $9-39$ \\
Eleven & $13.0+1.03(6)$ & $9-17$ & $6.0+0.0(1)$ & $6-6$ & $12.0+1.33(7)$ & $6-17$ \\
Twelve & $14.0+1.00(4)$ & $13-17$ & $9.0+0.0(1)$ & $9-9$ & $13.0+1.26(5)$ & $9-17$ \\
\hline Average & $10.1+0.78$ & $0-104$ & $9.4+0.59$ & $0-102$ & $9.7+0.48$ & $0-104$ \\
\hline
\end{tabular}

$\mathrm{SEM}=$ Standard error of mean $\quad *$ Indicates significant different between groups

\section{Narcotic Intake}

Table 8 illustrates narcotic intake and changes in three groups. Treatment groups showed reduction in narcotic intake, with heavy intake. Fig. 3 illustrates changes in narcotic intake in 3 groups, showing no narcotic intake and heavy intake.

\section{Employment Status}

Employment or work status is shown in Table 9. Patients

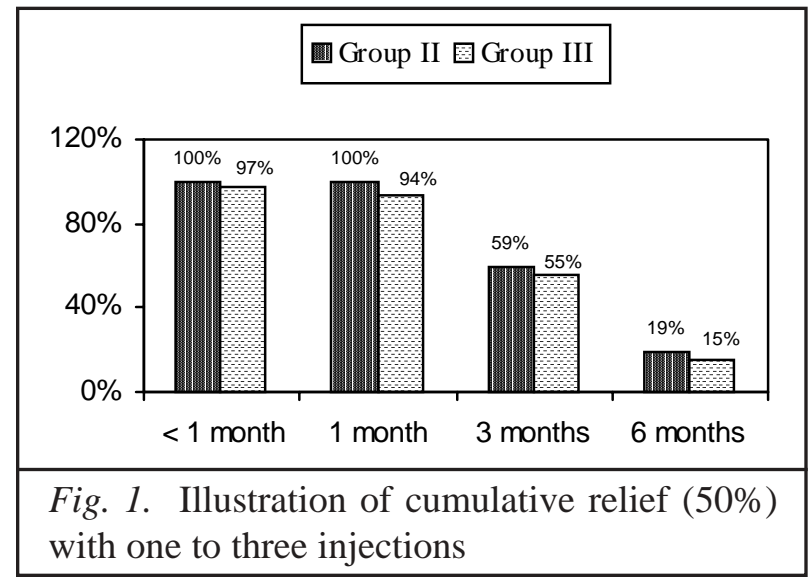

who were employed and unemployed were considered as candidates for future employment or continued employment. Housewives, disabled patients, and patients over 65 who were retired were considered not eligible for future employment. A total of 13 patients, 5 from group II and 8 from group III, became employed during the treatment period and continued to be employed at the end of the treatment period. The increase in employment and reduction in unemployment were significant in the treatment groups. Fig. 4 illustrates comparison of employment status prior to and following the treatment.

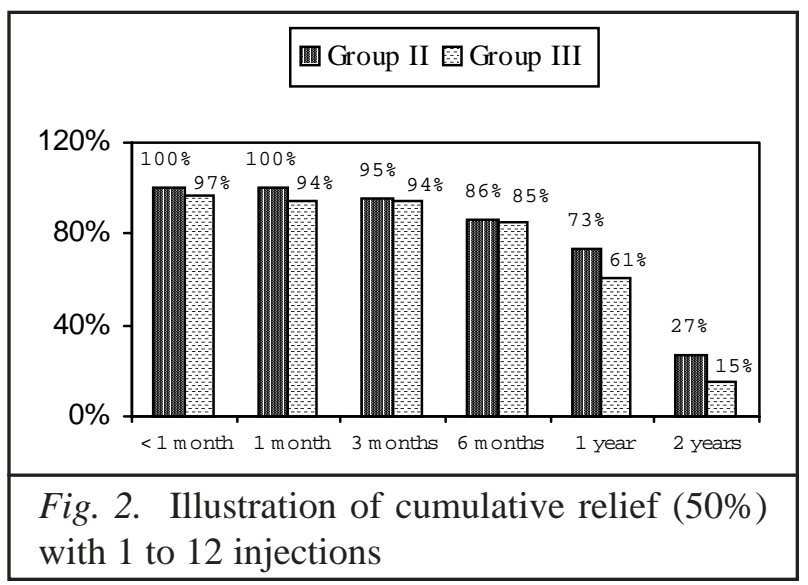


Table 6. Comparison of overall health status pre-and post-treatment

\begin{tabular}{lcccccc}
\hline & \multicolumn{2}{c}{ Group I } & \multicolumn{2}{c}{ Group II } & \multicolumn{2}{c}{ Group III } \\
\cline { 2 - 7 } & Pre & Post & Pre & Post & Pre & Post \\
Average pain & $7.0+0.22$ & $6.2+0.50$ & $7.6+0.23$ & $3.3^{*}+0.16$ & $7.9+0.21$ & $3.9^{*}+0.25$ \\
Physical health & $5.7+0.35$ & $5.8+0.31$ & $4.9+0.24$ & $7.0^{*}+0.18$ & $4.9+0.20$ & $6.4^{*}+0.21$ \\
Mental health & $5.6+0.16$ & $5.2+0.28$ & $4.6+0.21$ & $7.0^{*}+0.20$ & $4.9+0.24$ & $6.3^{*}+0.24$ \\
Functional status & $4.4+0.26$ & $4.6+0.34$ & $3.5+0.13$ & $5.6^{*}+0.16$ & $5.0+0.15$ & $5.2^{*}+0.17$ \\
\hline
\end{tabular}

* Indicates significant difference between pre- and post-treatment values

\section{Cost Effectiveness}

Cost effectiveness was analyzed, as shown in Table 10, for both treatment groups. The total cost was calculated for all procedures, including complications, in all patients. The number of weeks with significant relief was calculated as 1719 , with a mean relief of $10.1+0.78$ weeks per procedure for Group II, 2127 weeks, with a mean relief of $9.4+0.59$ weeks per procedure for Group III; and 3846 weeks, with a mean relief of $9.7+0.48$ weeks per procedure for both groups combined. Total expenditures were calculated from net collections, or the patient's expenses for the outpatient surgical center and physician fees as incurred by the insurer and/or the patient. The total cost per procedure was $\$ 487, \$ 341$, and $\$ 475$ for Groups II and III and a combination of Groups II and III, respectively. Further calculations showed that significant pain relief was provided with a cost-per-1-week improvement of quality of life in Group II of $\$ 48$, in Group III of $\$ 50$, and of $\$ 49$ for both groups combined. Calculation of these cost figures with conversion to a 1-year improvement of quality of life showed a cost of $\$ 2505$ for Group II, \$2586 for Group III, and \$2550 when combined for all patients, with no significant difference noted between groups. However, this cost-effectiveness analysis did not take into consideration the patients' return to work and various other benefits; nor did the cost-benefit ratio consider the money spent outside therapy for drugs or other types of treatments. In addition, the cost of the diagnostic blocks was also not included in this analysis.

\section{Complications}

None of the various types of complications, including infection, rash, reaction to drugs, epidural or subarachnoid blockade, postlumbar puncture headache, and/or weight gain, were observed in any patients.

\section{DISCUSSION}

The effects of caudal epidural steroid injections were first reported by Goebert and colleagues (31). They administered three injections of procaine and hydrocortisone into the epidural space to 239 patients with sciatica and reported greater than $60 \%$ relief of symptoms in $58 \%$ of the patients. Since that time, the technique and indications of epidural steroid injections have been changing constantly. Numerous reviews have appeared in the literature evalu-

Table 7. Psychological status of the patients pre-and post-treatment in three groups

\begin{tabular}{lcccccc}
\hline & \multicolumn{2}{c}{ Group I } & \multicolumn{2}{c}{ Group II } & \multicolumn{2}{c}{ Group III } \\
\cline { 2 - 7 } & Pre & Post & Pre & Post & Pre & Post \\
Depression & $50 \%(8)$ & $56 \%(9)$ & $82 \%(18)$ & $73 \%(16)$ & $85 \%(28)$ & $70 \%(23)$ \\
Generalized anxiety disorder & $63 \%(10)$ & $56 \%(7)$ & $82 \%(18)$ & $73 \%(16)$ & $82 \%(27)$ & $73 \%(24)$ \\
Somatization disorder & $50 \%(8)$ & $50 \%(8)$ & $41 \%(9)$ & $9 \% *(2)$ & $73 \%(24)$ & $33 \% *(11)$ \\
Symptom magnification & $50 \%(8)$ & $50 \%(8)$ & $41 \%(9)$ & $9 \% *(2)$ & $51 \%(17)$ & $27 \% *(9)$ \\
\hline
\end{tabular}

* Indicates significant difference between pre- and post-treatment values 
Table 8. Comparison of narcotic intake in pre-and post-treatment periods

\begin{tabular}{lcccccc}
\hline & \multicolumn{2}{c}{ Group I } & \multicolumn{2}{c}{ Group II } & \multicolumn{2}{c}{ Group III } \\
\cline { 2 - 7 } None & Pre & Post & Pre & Post & Pre & Post \\
Mild & $6 \%(1)$ & $0 \%$ & $0 \%$ & $14 \%(3)$ & $12 \%(4)$ & $15 \%(2)$ \\
Moderate & $19 \%(3)$ & $19 \%(3)$ & $9 \%(2)$ & $27 \%(6)$ & $6 \%(2)$ & $30 \%(10)$ \\
Heavy & $56 \%(9)$ & $44 \%(7)$ & $41 \%(9)$ & $55 \%(12)$ & $21 \%(7)$ & $39 \%(13)$ \\
* Indicates significant difference between pre- and post-treatment values & & & & $15 \% *(5)$ \\
\hline
\end{tabular}

ating the effectiveness of epidural steroid injections. The first systematic review of the effectiveness of epidural steroid injections was by Kepes and Duncalf in 1985 (14). They concluded that the rationale for epidural systemic steroids was not proven. However, in 1986 Benzon (15), utilizing the same studies, concluded that mechanical causes of low back pain, especially those accompanied by signs of nerve root irritation, may respond to epidural steroid injections. Bogduk et al (11) in an extensive review concluded that the balance of the published evidence supports the therapeutic use of caudal epidurals. Koes et al (9) in 1995 reviewed 12 trials of lumbar and caudal epidural steroid injections, with 5 studies involving caudal epidural steroid injections, of which 4 were positive. Watts and Silagy (12) in 1995, after a meta-analysis of the available data on epidural steroid injections, concluded that caudal and interlaminar epidural steroids were equally effective. Manchikanti et al (1), concluded that caudal epidural steroids met the criteria for moderate-to-strong evidence. Similar conclusions were drawn by McQuay and Moore (19). Extensive literature available on caudal epidural injections includes seven randomized trials (32-38), four prospective trials (39-42) and numerous uncontrolled

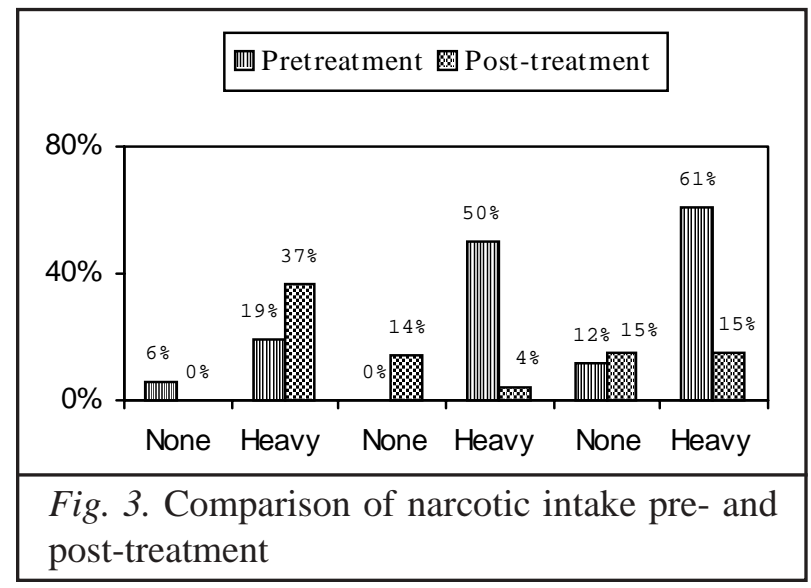

reports $(1,7,11,31,43-45)$. However, none of the controlled studies and only a small number of uncontrolled or observational reports were performed under fluoroscopy by interventional pain specialists. Of seven randomized trials, six were positive. In addition, multiple prospective and retrospective evaluations also provided favorable results consistent with randomized trials. Thus, it appears that caudal epidural steroid injections are an effective modality of treatment in managing chronic low back pain.

In this study, both groups of patients, with Sarapin or steroids, showed significant improvement in all parameters. Significant differences were noted between the control group and the treatment groups. Further, this study also showed that caudal epidural injections are cost-effective compared to numerous other modalities of treatments in managing low back pain.

Corticosteroids have been used since 1952 in the management of chronic low back pain by injecting them into the epidural space $(1,11)$. The rationale for steroid usage in neural blockade is primarily based on the benefits of neural blockade, including the pain relief which outlasts by

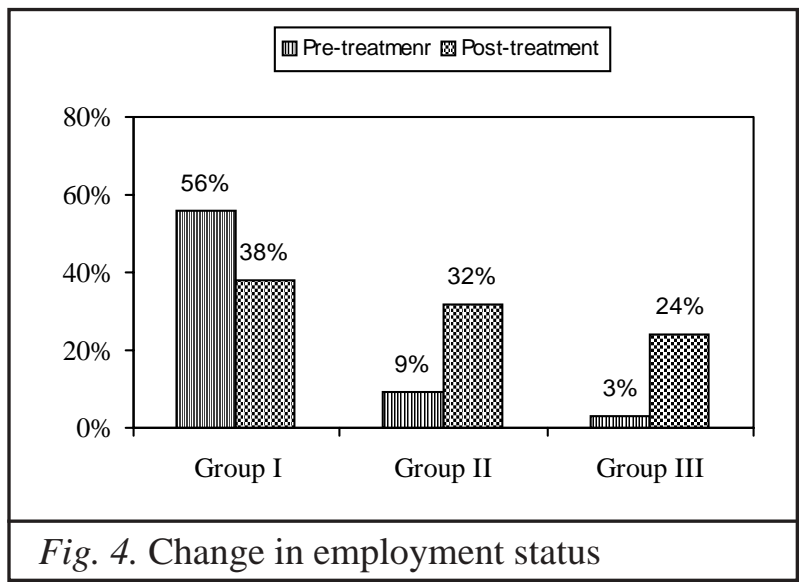


Table 9. Employment status of the patients pre-and post-treatment in three groups

\begin{tabular}{lcccccc}
\hline & \multicolumn{2}{c}{ Group I } & \multicolumn{2}{c}{ Group II } & \multicolumn{2}{c}{ Group III } \\
\cline { 2 - 6 } & Pre & Post & Pre & Post & Pre & Post \\
Employed & $56 \%(9)$ & $38 \%(6)$ & $9 \%(2)$ & $32 \%(7)$ & $3 \%(1)$ & $24 \% *(8)$ \\
Unemployed & $19 \%(3)$ & $31 \%(5)$ & $18 \%(4)$ & $0 \%$ & $10 \%(3)$ & $6 \%(2)$ \\
Housewife & $6 \%(1)$ & $6 \%(1)$ & $5 \%(1)$ & $5 \%(1)$ & $0 \%(0)$ & $0 \%$ \\
Disabled & $6 \%(1)$ & $13 \%(2)$ & $41 \%(9)$ & $36 \%(8)$ & $46 \%(15)$ & $49 \%(16)$ \\
Over $>65($ retired) & $13 \%(2)$ & $13 \%(2)$ & $27 \%(6)$ & $27 \%(6)$ & $21 \%(7)$ & $21 \%(7)$ \\
\hline
\end{tabular}

* Indicates significant difference between pre- and post-treatment values

hours, days, and sometimes weeks, the transient pharmacologic action of other adjuvant agents such as local anesthetics and others. While there are no clear-cut explanations for these benefits available currently, it is believed that neural blockade alters or interrupts nociceptive input, reflex mechanism of the afferent limb, self-sustaining ac- tivity of the neuron pools and neuraxis, and the pattern of central neuronal activities (46). Corticosteroids reduce inflammation either by inhibiting the synthesis or release of a number of pro-inflammatory substances (1). Various modes of action of corticosteroids include membrane stabilization; inhibition of neural peptide synthesis or action;

Table 10. Analysis of cost-effectiveness of epidural injections

Number of patients

Total number of procedures

Number of treatments per patient (mean + SEM)

Visits with significant relief $(>50 \%)$

Number of weeks with significant relief for all patients in the study in weeks

Significant relief in weeks per procedure (mean + SEM)

\section{Total Cost $(\$)$}

Physician

Facility

Total

\section{Cost per procedure (\$)}

Physician

Facility

Total

Cost for 1-week improvement of quality of life (\$)

\begin{tabular}{ccc} 
Group II & Group III & Total \\
\hline 22 & 33 & 55 \\
170 & 227 & 397 \\
$7.7+0.70$ & $6.9+0.5$ & $7.2+0.41$ \\
$98 \%$ & $98 \%$ & $98 \%$ \\
1719 & 2127 & 3846 \\
$10.1+0.78$ & $9.4+0.59$ & $9.7+0.48$ \\
& & \\
23,128 & 28,318 & 51,446 \\
59,684 & 77,441 & 137,125 \\
\hline 82,812 & 105,759 & 188,571
\end{tabular}

SEdst-fôtandtayearrimproveament of quality of life (\$)

\begin{tabular}{ccc}
136 & 125 & 130 \\
351 & 341 & 345 \\
\hline 487 & 466 & 475 \\
48 & 50 & 49
\end{tabular}

2,505

2,586

2550 
blockade of phospholipase $\mathrm{A}_{2}$ activity; prolonged suppression of ongoing neuronal discharge; suppression of sensitization of dorsal horn neurons; and reversible local anesthetic affect (1). The scientific basis of some of these concepts, at least in part, is proven for spinal pain management with epidural injections of betamethasone, and IV methylprednisolone (47-52).

Sarapin is a suspension of powdered Sarracenia purpurin (pitcher plant) in alkaline solution. The value of Sarapin in relieving pain of neurologic origin was reported by Bates and Judovich in $1931(53,54)$. However, clinical investigations of this unique product for epidural administration are lacking. Sarapin has been reported to cause no motor weakness following injection of the peripheral nerve; it also does not cause or affect loss of touch, pressure, pinprick, or temperature sensibility and has an excellent risk/benefit ratio. Controlled studies with procaine, saline, and water show prolonged duration of effect in favor of the pitcher-plant preparation (54). The basis of the pitcher plant derivative, or Sarapin, was explained by experiments performed on the action potentials of the saphenous nerve of the cat, which showed that the C-fiber potential was completely obliterated by pitcher-plant extract after immersion in the solution for about 5 minutes. Researchers theorize that the distillate contained an unidentified biological substance that potentiates the action of the ammonium ion. Modest but significant benefits were demonstrated with diagnostic blocks utilizing Sarapin, which provided not only diagnostic validity, but also therapeutic value (28). Significant therapeutic effect was seen with Sarapin when utilized in medial branch blocks, which was similar to the relief seen with a mixture of Sarapin and methylprednisolone (29). However, the lack of local anesthetic efficacy of Sarapin was demonstrated in the horse (55). Harkins et al (55) demonstrated that Sarapin has no significant classic or local anesthetic actions in the horse, and probably not in other species either. However, this finding is not surprising as Sarapin has been demonstrated to relieve pain of neurologic origin, but not by local anesthetic action.

This study was prospective, even though it was not blinded. Issues of ethics, feasibility, cost, and reliability pose challenges to a double-blind trial in interventional pain medicine. Concato et al (56) found that well-designed observational studies do not systematically overestimate the magnitude of effects of treatments as compared with those in randomized, controlled trials on the same topic. In addition, Schulz et al (57) also postulated that lack of randomization overestimates the treatment effects by $41 \%$, whereas lack of blinding overestimates the treatment effect only by $17 \%$.

The cost effectiveness analysis may be criticized for various reasons. However, the outcome measures used in costeffectiveness analysis studies in chronic pain research mainly include outcomes, such as disability days saved; pain free days; or improved quality of life, etc. (58). Evaluation of the quality of life, which is also known as functional status, includes health status, or health related quality of life; well-being of the patient; satisfaction with care and health service utilization/economic analysis, and medical findings (59). The quality of life assessment is designed to evaluate the patient's ability to function in his/her own world. Physical function measures the ability to perform physical activities such as walking, climbing stairs or carrying things. The costs of an inpatient chronic pain program range from $\$ 17,000$ to $\$ 25,000$. The costs of outpatient treatment programs range from $\$ 7,000$ to $\$ 10,000$ in 1989 dollars, without consideration of inflation; and chronic pain patients may incur health-care bills in excess of $\$ 20,000$ annually for repetitive and, in some cases, redundant diagnostic workups, physical therapy, psychological interventions, and drugs (60). Guo et al (61) estimated that back pain accounted for 150 million lost workdays in the United States every year, which worked out to be about $\$ 14$ billion in wage costs alone. They also postulated that the magnitude of the back pain problem is so large that even a $1 \%$ reduction in overall prevalence could considerably reduce morbidity and save billions of dollars.

The cost effectiveness of lumbar discectomy for the treatment of herniated intervertebral discs has been based on the conclusion that surgery increases the average qualityadjusted life expectancy by 0.43 years during the decade following treatment; compared to conservative treatment, a result comparable to extending a healthy life by 5 months (62). Malter et al (62) also concluded that, for carefully selected patients with herniated discs, surgical discectomy is a cost-effective treatment at a discounted cost of $\$ 12,000$ per discectomy, or $\$ 29,000$ per life year adjusted for quality. Kuntz et al (63) studied the cost effectiveness of fusion with and without instrumentation for patients with degenerative spondylolisthesis and spinal stenosis. They showed that laminectomy with a noninstrumented fusion costs $\$ 56,500$ per quality-adjusted year of life versus laminectomy without fusion. The cost-effectiveness ratio of instrumented fusion compared with noninstrumented fusion was $\$ 3,112,800$ per quality-adjusted year of life. However, they also stated that, if the proportion of patients experiencing symptom relief after instrumented fu- 
sion was $90 \%$, as compared with $80 \%$ for patients with noninstrumented fusion, then the cost-effectiveness ratio of instrumented fusion compared with noninstrumented fusion would be $\$ 82,400$ per quality-adjusted year of life. Mueller-Schwefe et al (64), in evaluating the cost-effectiveness of intrathecal therapy for pain secondary to failed back surgery syndrome, compared alternative therapies for achieving a defined outcome, reporting the cost of medical management to be $\$ 17,037$ per year or $\$ 1,420$ per month. They also showed that intrathecal morphine delivery resulted in lower cumulative 60-month costs of $\$ 16,579$ per year, and $\$ 1,382$ per month.

The cost-effectiveness evaluation for blind interlaminar, fluoroscopically directed caudal or transforaminal epidural injections for the management of low back pain showed the cost effectiveness of caudal epidural steroids to be $\$ 3,635$ and that of transforaminal steroids to be $\$ 2,927$ per year, with a stark contrast with blind interlaminar lumbar epidural steroid injections at $\$ 6,024$ per year (45). Similarly, the cost effectiveness of percutaneous nonendoscopic adhesiolysis and hypertonic saline neurolysis was demonstrated to be variable, from \$2028 to \$5564 for improvement of 1 year of quality of life for patients with chronic low back pain nonresponsive to numerous other modalities of treatment (65-67). The cost effectiveness of therapeutic medial branch blocks was shown as $\$ 3,461$ for 1 year of quality of life improvement for patients with chronic low back pain nonresponsive to conservative modalities of treatments, and the diagnosis of lumbar facet joint pain was confirmed by controlled comparative local anesthetic blocks (29). Thus, cost effectiveness analysis of this evaluation with caudal epidural injections with $\$ 2550$ for 1 year of improvement in the quality of life is similar to various investigations in the past with neural blockade but also significantly better than improvement with intrathecal morphine delivery, lumbar laminectomy, on lumbar laminectomy with or without instrumented fusion. In addition, interpretation of the current results should be placed in the context of not only other interventional procedures, but also surgery and other modalities of treatments. Therefore, caudal epidural injections with Sarapin or steroids for patients suffering with chronic low back pain with or without lower extremity pain have a cost-effectiveness ratio not only in the same approximate range as that of other well-accepted modalities of treatment in managing chronic low back pain, but, also well within reasonable limits for present-day costeffective management of other medical conditions $(29,58$ 71).

\section{CONCLUSION}

Caudal epidural injections are an effective modality of treatment in managing chronic low back pain after exclusion of facet joint pain. Caudal epidural injections with or without steroid but with local anesthetic and Sarapin are effective in providing significant pain relief, improvement in functional status, improvement in overall psychological status, and return to work. Caudal epidural injections also have exerted modest but statistically insignificant effect on the patient's state of depression, anxiety, symptom magnification and somatization. It is concluded that caudal epidural injections with Sarapin or with steroid are an effective modality of treatment in managing chronic low back pain without facet joint involvement.

\section{ACKNOWLEDGMENTS}

We would like to thank Marla K. Neihoff and Lori A. Rose, medical records coordinators, for their assistance in collection of data. We would also like to thank Denise Pratt and Tonie Hatton, transcriptionists, for their assistance with transcription of the manuscript.

\section{REFERENCES}

1. Manchikanti L, Singh V, Kloth D et al. Interventional techniques in the management of chronic pain. Part 2.0. Pain Physician 2001; 4:24-96.

2. Manchikanti L. Dr. No. Managed care: Clinical guidelines. Pain Physician 2000; 3:3-6.

3. Bigos SJ, Boyer OR, Braen GR et al. Acute Low Back Problems in Adults. Clinical Practice Guideline Number 4. AHCPR Publication No. 95-0642. Rockville, Agency for Health Care Policy and Research, Public Health Service, US Department of Health and Human Services, December 1994.

4. Practice guidelines for chronic pain management. A report by the American Society of Anesthesiologists Task Force on Pain Management, Chronic Pain Section. Anesthesiology 1997; 86:995-1004.

5. Sanders SH, Rucker KS, Anderson KO et al. Clinical practice guidelines for chronic non-malignant pain syndrome patients. J Back Musc Rehabil 1995; 5:115120.

6. Sanders SH, Harden RN, Benson SE et al. Clinical practice guidelines for chronic non-malignant pain syndrome patients II: An evidence-based approach. $J$ Back Musc Rehabil 1999; 13:47-58.

7. American Geriatrics Society. The management of chronic pain in older persons: New guidelines from the American Geriatrics Society. J Am Geriatr Soc 1998; 46:128-150. 
8. Abram SE. Current guidelines in the use of epidural steroids in the United States of America. Pain Digest 1999; 9:233-234.

9. Koes BW, Scholten RJPM, Mens JMA et al. Efficacy of epidural steroid injections for low back pain and sciatica: A systematic review of randomized clinical trials. Pain 1995; 63:279-288.

10. Koes BW, Scholten R, Mens JMA et al. Epidural steroid injections for low back pain and sciatica. An updated systematic review of randomized clinical trials. Pain Digest 1999; 9:241-247.

11. Bogduk N, Christophidis N, Cherry D et al. Epidural use of steroids in the management of back pain. Report of working party on epidural use of steroids in the management of back pain. National Health and Medical Research Council. Canberra, Commonwealth of Australia, 1994, pp 1-76.

12. Watts RW, Silagy CA. A meta-analysis on the efficacy of epidural corticosteroids in the treatment of sciatica. Anaesth Intens Care 1995; 23:564-569.

13. Mugford HK. Conflicting conclusions from two systematic reviews of epidural steroid injections for sciatica: Which evidence should general practitioners heed? Br J Gen Pract 1999; 49:57-61.

14. Kepes ER, Duncalf D. Treatment of backache with spinal injections of local anesthetics, spinal and systemic steroids. Pain 1985; 22:33-47.

15. Benzon HT. Epidural steroid injections for low back pain and lumbosacral radiculography. Pain 1986; 24:277.

16. Bogduk N. Epidural steroids for low back pain and sciatica. Pain Digest 1999; 9:226-227.

17. Benzon HT, Molly RE. Outcomes, efficacy, and compliances from management of low back pain. In Raj PP, Abrams BM, Benzon HT et al (eds). Practical Management of Pain, ed 3. Mosby, Philadelphia, 2000, pp 891-903.

18. Gonzalez EG, Materson (eds). The Nonsurgical Management of Acute Low Back Pain. Demos Vermane, New York, 1997.

19. McQuay HJ, Moore RA. Epidural corticosteroids for sciatica. An Evidence-Based Resource for Pain Relief. Oxford University Press, New York, 1998, pp 216-218.

20. Manchikanti L. Epidemiology of low back pain. Pain Physician 2000; 3:167-192.

21. Lawrence RC, Helmick CG, Arnett FC. Estimates of the prevalence of arthritis and selected musculoskeletal disorders in the United States. Arthritis \& Rheumatism 1998; 41:778-799.

22. Cassidy D, Carroll L, Cote P. The Saskatchewan Health and Back Pain Survey. The prevalence of low back pain and related disability in Saskatchewan adults. Spine 1998; 23:1860-1867.

23. Sicard MA. Les injections medicamenteuse extraduraqles per voie saracoccygiene. Comptes Renues des Senances de la Societe de Biolgie et de ses Filliales, 1901; 53:396-398.

24. Pasquier NM, Leri D. Injection intra-et extradurales de cocaine a dose minime daus le traitment de la sciatique. Bull Gen Ther 1901; 142:196.

25. Pages E. Anesthesia metamerica. Rev Sanid Mil Madr 1921; 11:351-385.

26. Manchikanti L. Transforaminal lumbar epidural steroid injections. Pain Physician 2000; 3:374-398.

27. Kuslich SD, Ulstrom CL, Michael CJ. The tissue origin of low back pain and sciatica: A report of pain response to tissue stimulation during operation on the lumbar spine using local anesthesia. Orthop Clin North Am 1991; 22:181-187.

28. Manchikanti L, Pampati VS, Bakhit CE et al. The diagnostic validity and therapeutic value of lumbar facet joint nerve blocks with or without adjuvant agents. Cur Rev Pain 2000; 4:337-344.

29. Manchikanti L, Pampati V, Bakhit CE et al. Effectiveness of lumbar facet joint nerve blocks in chronic low back pain: A randomized clinical trial. Pain Physician 2001; 4:101-117.

30. Manchikanti L, Pampati V, Fellows B et al. The inability of the clinical picture to characterize pain from facet joints. Pain Physician 2000; 3:158-166.

31. Goebert HW, Jallo SJ, Gardner WJ et al. Painful radiculopathy treated with epidural injections of procaine and hydrocortisone acetate results in $113 \mathrm{pa}-$ tients. Anesth Analg 1961; 140:130-134.

32. Breivik H, Hesla PE, Molnar I et al. Treatment of chronic low back pain and sciatica. Comparison of caudal epidural injections of bupivacaine and methylprednisolone with bupivacaine followed by saline. In Bonica JJ, Albe-Fesard D (eds). Advances in Pain Research and Therapy. Raven Press, New York, 1976, Vol. 1, pp 927-932.

33. Bush K, Hillier S. A controlled study of caudal epidural injections of triamcinolone plus procaine for the management of intractable sciatica. Spine 1991; 16:572-575

34. Matthews JA, Mills SB, Jenkins VM et al. Back pain and sciatica: Controlled trials of manipulation, traction, sclerosant and epidural injections. Brit $J$ Rheumatol 1987; 26:416-423.

35. Beliveau P. A comparison between epidural anesthesia with and without corticosteroids in the treatment of sciatica. Rheum Phys Med 1971; 11:40-43.

36. Czarski Z. Leczenie rwy kulszowej wstrzykiwaniem hydrokortyzonu inowokainy do rozworu kryzowego. Przeglad Kekarski 1965; 21:511-513.

37. Revel M, Auleley GR, Alaoui S et al. Forceful epidural injections for the treatment of lumbosciatic pain with post-operative lumbar spinal fibrosis. Rev Rhum Engl Ed 1996; 63:270-277.

38. Meadeb J, Rozenberg S, Duquesnoy B et al. Forceful sacrococcygeal injections in the treatment of 
postdiscectomy sciatica. A controlled study versus glucocorticoid injections. Joint Bone Spine 2001; 68:4349.

39. Yates DW. A comparison of the types of epidural injection commonly used in the treatment of low back pain and sciatica. Rheum Rehab 1978; 17:181-186.

40 Swerdlow M, Sayle-Creer W. A study of extradural medication in the relief of the lumbosciatic syndrome. Anaesthesia 1970; 25:341-345.

41. Waldman SD. The caudal epidural administration of steroids in combination with local anesthetics in the palliation of pain secondary to radiographically documented lumbar herniated disc: A prospective outcome study with 6-months follow-up. Pain Clin 1998; 11:4349.

42. White AH, Derby R, Wynne G. Epidural injections for the diagnosis and treatment of low-back pain. Spine 1980; 5:78-86.

43. Apathy, A, Penczner G, Licker E et al. Caudal epidural injection in the management of lumbosacral nerve pain syndromes. Orv Hetil 1999; 140:1055-1058.

44. Ciocon JO, Galindo-Clocon D, Amarnath L et al. Caudal epidural blocks for elderly patients with lumbar canal stenosis. J Am Geriatr Soc 1994; 42:593-596.

45. Manchikanti L, Pakanati RR, Pampati V. Comparison of three routes of epidural steroid injections in low back pain. Pain Digest 1999; 9:277-285.

46. Fox AJ, Melzack R. Transcutaneous electrical stimulation to acupuncture. Comparison of treatment of low back pain. Pain 1976; 2:141-148.

47. Olmarker K, Byrod G, Cornefijord M et al. Effects of methylprednisolone on nucleus pulposus-induced nerve root injury. Spine 1994; 19:1803-1808.

48. Hayashi N, Weinstein JN, Meller ST et al. The effect of epidural injection of betamethasone or bupivacaine in a rat model of lumbar radiculopathy. Spine 1998; 23:877-885.

49. Lee HM, Weinstein JN, Meller ST et al. The role of steroids and their effects on phospholipase $\mathrm{A}_{2}$. An animal model of radiculopathy. Spine 1998; 23:11911196.

50. Minamide A, Tamaki T, Hashizume H et al. Effects of steroids and lipopolysaccharide on spontaneous resorption of herniated intervertebral discs. An experience study in the rabbit. Spine 1998; 23:870-876.

51. Kingery WS, Castellote JM, Maze M. Methylprednisolone prevents the development of autotomy and neuropathic edema in rats, but has no effect on nociceptive thresholds. Pain 1999; 80:555-566.

52. Byrod G, Otani K, Brisby H et al. Methylprednisolone reduces the early vascular permeability increase in spinal nerve roots induced by epidural nucleus pulposus application. J Orthop Res 2000; 18:983-987.

53. Bates W, Judovich BD. Intractable pain. Anesthesiology 1942; 3:663-672.

54. Judovich BD, Bates W. Pain syndromes. Treatment by paravertebral nerve block. Philadelphia, FA Davis, 1950; pp 242-249.

55. Harkins JD, Mundy GD, Stanley SD et al. Lack of local anesthetic efficacy of Sarapin in the abaxial sesamoid block model. J Vet Pharmacol Ther 1997; 20:229-232.

56. Concato J, Shah N, Horwitz RI. Randomized, controlled trials, observational studies, and the hierarchy of research designs. N Engl J Med 2000; 342:18871892.

57. Schulz KF, Chambers I, Hayes RJ et al. Empirical evidence of bias: Dimensions of methodological quality associated with estimates of treatment effects on controlled trials. JAMA 1995; 273:408-412.

58. Goossens MEJB, Evers SMAA, Vlaeyen JWS et al. Principles of economic evaluation for interventions of chronic musculoskeletal pain. Eur J Pain 1999; 3:343353.

59. Hopwood M. Outcomes assessment in pain management. In Abram SE (ed). Pain Management. Churchill-Livingstone, Philadelphia, 1998, pp 14.114.11.

60. Cicala RS, Wright H. Outpatient treatment of patients with chronic pain. Analysis of cost savings. Clin J Pain 1989; 5: 223-226.

61. Guo HR, Tanaka S, Halperin WE et al. Back pain prevalence in US industry and estimates of lost work days. Am J Public Health 1999; 89:1029-1035.

62. Malter AD, Larwon EB, Urban $\mathrm{N}$ et al. Cost-effectiveness of lumbar discectomy for the treatment of herniated intervertebral disc. Spine 1996; 21:1048-1055.

63. Kuntz K, Snider R, Weinstein J et al. Cost-effectiveness of fusion with and without instrumentation for patients with degenerative spondylolisthesis and spinal stenosis. Spine 2000; 25: 1132-1139.

64. Mueller-Schwefe G, Hassenbusch SJ, Reig E. Costeffectiveness of intrathecal therapy for pain. Neuromodulation 1999; 2:77-84.

65. Manchikanti L. Pakanati RR, Bakhit CE et al. Role of adhesiolysis and hypertonic saline neurolysis in management of low back pain. Evaluation of modification of Racz protocol. Pain Digest 1999; 9:91-96.

66. Manchikanti L, Pampati V, Fellows B et al. Role of one day epidural adhesiolysis in management of chronic low back pain: A randomized clinical trial. Pain Physician 2001; 4:153-166.

67. Manchikanti L, Pakanati RR, Bakhit CE et al. Nonendoscopic and endoscopic adhesiolysis in post lumbar laminectomy syndrome. A one-year outcome study and cost effectiveness analysis. Pain Physician 1999; 2:52-58.

68. Lave JR, Frank RG, Schulberg HC et al. Cost-effectiveness of treatments for major depression in primary care practice. Arch Gen Psychiatry 1998; 55:645-651. 69. Chang RW, Pellissier JM, Hazen GB. A cost-effectiveness analysis of total hip arthroplasty for osteoar- 
thritis of the hip. JAMA 1996; 275:858-865.

70. Wong JB, Sonnenberg FA, Salem DN et al. Myocardial revascularization for chronic stable angina: Analysis of the role of percutaneous transluminal coronary angioplasty based on data available in 1989. Ann In- tern Med 1990; 113:852-871.

71. Katz DA, Cronenwett JL. The cost effectiveness of early surgery versus watchful waiting in the management of small abdominal aortic aneurysms. J Vasc Surg 1994; 19:980-991. 